\title{
Die Wahrnehmung des Reformators Primus Truber zu Lebzeiten und danach
}

\author{
von VINCENC RAJŠP
}

\section{Primus Truber - sein Leben}

Truber lebte in zwei Zeiten und Welten, in einer Zeit und in der Welt von Reformationsideen in den Jahren 1530-1547 und 1562-1564 in seiner slowenischen Heimat sowie in einer Zeit des durchgesetzten Protestantismus in den deutschen Ländern (1548-1560 und 1565-1586). Bei seiner Rückkehr nach Krain im Jahr 1562 sah er noch reelle Möglichkeiten für einen reformations-protestantischen Wandel der Heimat. Kaiser Ferdinand war „ein wichtiger Exponent der zwischen den Konfessionsparteien betriebenen Ausgleichspolitik" ${ }^{1}$ doch als Förderer galt König Maximilian. Truber war überzeugt davon, dass er nicht gegen Ferdinands Glaubenspolitik predige, als Beispiel erwähnt er die Abschaffung von katholischen Feiertagen im Jahr 1524, der er zustimmt, und nicht die katholischen Priester, die sich der Abschaffung widersetzten. Entscheidend war jedoch, dass er die Unterstützung der krainischen Landstände, die ihn 1561 als Prediger in die Heimat berufen hatten, sowie jene des Laibacher Bürgertums hatte. Die Möglichkeit der Einführung der Reformation signalisiert auch die unentschlossene Haltung des Bischofs von Laibach/Ljubljana, Peter Seebach, von dem Truber hoffte, dass er gleich reagieren würde wie die Bischöfe in Magdeburg und Halle in Sachsen, die ihre Bistümer gemäß dem Augsburger Bekenntnis reformierten. ${ }^{2}$

Primus Truber wurde um 1508 oder 1507, möglicherweise auch 1509 geboren. ${ }^{3}$ 1526 wurde sein Familienname in Triest als Trubar eingetragen, im Jahr 1528 wurde er an der Wiener Universität als Primus Truber immatrikuliert und unterschrieb sich dann sein ganzes Leben lang so. Bei den Slowenen blieb seine erste Namensform, Trubar, erhalten. ${ }^{4}$ Er wurde in der Pfarre St. Kanzian bei Auersperg/Škocjan pri Turjaku in Unterkrain geboren, deren Patronat die Grafen Auersperg innehatten, die diese Pfarre dann im Jahr 1563 reformierten.

1 Alfred Kohler: Ferdinand I. 1503-1564 Fürst, König und Kaiser. München 2003, S. 203.

2 Jože Rajhman: Pisma Primoža Trubarja. Ljubljana 1986, S. 109.

3 Boris Golec: Neue Erkenntnisse über die Herkunft und Identität von Primus Truber (Primož Trubar). In: Primus Truber. Der slowenische Reformator und Württemberg. Hg.: Sönke Lorenz, Anton Schindling, Wilfried Setzler. Stuttgart 2011, S. 79-92.

4 Ebd., S. 87. 
Die Grundlagen im Schreiben erhielt Truber bei seinem Landpfarrer, setzte die Ausbildung im Jahr 1521 in Fiume/Rijeka (St. Veit am Pflaum) fort, dann in Salzburg, ${ }^{5}$ und kam 1524 zu Bischof Pietro Bonomo nach Triest, der Zöglinge in Theologie ausbildete. Der Unterricht war sehr modern. Truber wurde mit den Paraphrasen des Erasmus und mit Calvins Institutiones bekannt gemacht. Der Unterricht erfolgte in drei lebenden Sprachen: in Walscher / Teutscher und Windischer sprach. ${ }^{6}$ Ein Jahr lang - 1528 - studierte Truber an der Wiener Universität. Dort war er Zeuge der Verbrennung Balthasar Hubmayers auf dem Scheiterhaufen, was sich bei ihm stark einprägte. ${ }^{?}$

Nach seiner Priesterweihe im Jahr 1530 wirkte Truber im Predigerdienst an bedeutenden Plätzen, wie in der angesehenen Pfarre Tüffer/Laško, nach 1533 als slowenischer Prediger im Dom von Laibach, dann im Triestiner Dom, dann wieder in Laibach, als ihn 1542 König Ferdinand zum Domherren im Laibacher Domkapitel ernannte.

Wie er im Jahr 1582 schrieb, fasste er den Predigerdienst als seine grundlegende Mission auf: Ich, der nun 74 Jahre alt bin, war 52 Jahre davon Prediger. ${ }^{8} \mathrm{Er}$ predigte im Geist der Reformideen der schweizerischen und deutschen protestantischen Theologen und gegen die geltenden Glaubensgewohnheiten der einfachen Gläubigen.

Im Domkapitel von Laibach, das im Statut im Jahr 1533, vor der Ankunft Trubers, bestimmte, dass die Evangelienwahrheit bei der Domkirche „rein, einfach und getreu" verkündet werden soll, waren die Reformideen stark. ${ }^{9}$ Es kann gesagt werden, dass sie im Land Krain allgemein vorhanden waren, doch der Landesfürst Erzherzog Ferdinand, die Priester, der Adel, das Bürgertum und die einfachen Gläubigen haben sie sich jeweils unterschiedlich vorgestellt. Der Adel und das Bürgertum entschieden sich für jene aus den deutschen Ländern, der Erzherzog Ferdinand jedoch verbot streng die Verbreitung von Luthers Lehren.

5 Mirko Rupel: Primus Truber. Leben und Werk des slowenischen Reformators. Deutsche Übersetzung und Bearbeitung von Balduin Saria. München 1965, S. 16.

6 Primus Truber: Ta Pervi Deil Tiga Noviga Testamenta. Vtim So vsi Shtyri Evangelisti inu Tv Diane tih Iogrou, sdai peruizh vta Slouenski Iesik, Skusi Primosha Truberia sueistu preobernen. Der erste halber Teil des newen Testaments [...] in die gemeine Windische Sprach jetzund zum ersten mal fleissig verdolmetscht. [...] Tubingae anno 1557, S. IV a.

7 Primus Truber: Catechismus sdveima islagama, ena pridiga od starosti te praue inu kriue vere, [...] / Catechismus mit des Herrn Brentij vnd M.C. Vischers außlegung, ein Predig vom Vrsprung vnd Alter deß rechten vnd falschen Glaubens vnd Gottesdiensts, die Haußtaffel, vnnd die kleine Agenda. V Tibingi 1575, S. 241.

8 Primus Truber: Ta celi Noui Testament nashiga gospudi inu isvelizharie Iesusa Cristusa, na dua maihina deilla resdilen, vtim ie tiga stariga Testamenta dopolnene, summa inu praua islaga, druguzh pregledan inu vkupe drukan, skusi Primosa Truberia Crainza Rastzhizheria. / Das new Testament vnsers Herren vnd Seligmachers Jesu Christi, in zwen klein theil abgetheilt, in welchem des alten Testaments Erfüllung, Summa vnd rechte Außlegung begriffen, zum andern mal vbersehen vnd zusamen getruckt. V Tibingi 1582, S. 7 b.

9 Lilijana Žnidaršič Golec: Der Klerus der Laibacher Domkirche und die protestantische Reformation bis Bischoif Peter Seebach (1560-1568). In: Südostdeutsches Archiv XLVI/XLVII (2003/04), S. 1-12, hier 2. 
In den Jahren 1523-1563 gab er ungefähr 50 Mandate heraus, ${ }^{10}$ in denen ,,sich er auf das Wormser Edikt berief und verbot Druck, Verkauf, das Lesen und Abschreiben aller bisher erschienenen und künftig erscheinenden Schriften Luthers und seiner Nachfolger" ${ }^{6}{ }^{11}$ Auf die meisten dieser Delikte stand die Todesstrafe. ${ }^{12}$ Eigene Patente erließ Ferdinand zum Buchwesen, (z.B. das vom 24. Juli 1528) betreffend die ketzerischen Schriften, die Buchdrucker und Verkäufer sollten streng bestraft werden. ${ }^{13}$ Das einfache Volk zeigte trotz Krisenzeiten außerordentliche Energie bei der Errichtung von neuen Kirchen, die als Wallfahrtsorte und auch als Zufluchtsstätten vor den Türken dienten, und lehnte die Abschaffung der gebotenen Feiertage natürlich ab.

Ferdinand trat im Jahr 1547 entschiedener auf, als er verlangte den Großteil der Laibacher Kanoniker zu verhören; ebenso Paul Wiener ${ }^{14}$ in Wien (wo dieser dann freigesprochen wurde, sich nach Siebenbürgen absetzte und dort der erste Superintendent wurde), während sich Truber nach Nürnberg, zu Veit Dietrich zurückzog, der ihm die Stelle eines Predigers in Rothenburg ob der Tauber beschaffte. Dort heiratete Truber die aus Krainburg/Kranj stammende Barbara Sitar, was auch nach außen einen Bruch mit der katholischen Kirche bedeutete. Truber befasste sich nun, nachdem er sich vom Land Krain zurückgezogen hatte, mit den neuen technischen Möglichkeiten - mit dem Druck. Die ersten beiden slowenischen Bücher, Catechismus und Abecedarium, wurden im Jahr 1550 hier in Schwäbisch Hall gedruckt, was wir erst vor Kurzem erfuhren.

In der nächsten Prediger-Stadt Kempten setzte er die Bucharbeit fort und gab neben dem Katechismus auch das Evangelium des H1. Matthäus heraus. Eine weitere Station war im Jahr 1560 Urach, wo ein unglaubliches Unternehmen entstand, das für den Druck von Religionsbüchern für die Slowenen und slawischen Christen in Kroatien, aber auch für jene unter den Türken in Bosnien in lateinischer und cyrillischer Schrift, und ebenso für Dalmatien in glagolitischer Schrift, die dort in der slawischen Liturgie überwog, bestimmt war. ${ }^{15}$ Das Unternehmen wurde von Truber geleitet, und der wichtigste Geldgeber war Hans Ungnad, ein Adliger aus der Steiermark und dort auch Feldherr gegen die Türken, und der zweitwichtigste Geldgeber war der Württembergische Herzog Christoph. Wegen seiner Drucke und der Druckerei von Urach wurde Trubers Name den deutschen Fürsten und König Maximilian bekannt.

Im Jahr 1560 kam Truber einer Einladung für einen Predigerposten nach Ljubljana nach, organisierte dort eine evangelische Kirche, schrieb für sie eine Kir-

10 Kohler (wie Anm. 1), S. 189.

11 Ebd., S. 185.

12 Ebd., S. 190.

13 Ebd., S. 191.

14 Karl W. Schwarz: Paul Wiener. In: Biographisch-bibliographisches Kirchenlexikon. Bd. 38. Nordhausen 2017.

15 Hermann Ebner: Primus Truber, Hans Ungnad von Sonneg und die Uracher Druckerei 1560 1564. In: Lorenz/Schindling/Setzler (wie Anm. 3), S. 201-216. 
chenordnung, weswegen ihn der neue Landesfürst Erzherzog Karl II. aus dem Land verwies. Er wandte sich nach Lauffen und dann nach Derendingen, wo er bis zu seinem Tod im Jahr 1586 Pfarrer war.

Truber schrieb, bearbeitete oder übersetzte 26 Bücher ins Slowenische (er übersetzte das Neue Testament, Psalmen, Gesangbücher, Katechismen, theoretische Liturgie-Aufsätze, Postillen, Gebete und Kalender), die Kirchenordnung für Kempten und verfasste zehn deutsche Widmungen für kroatische Bücher. ${ }^{16} \mathrm{Im}$ Jahr 1582 bezeichnete er diejenigen Bücher als bedeutende Werke, die notwendig sind, um das Heil zu erreichen: den theologischen Aufsatz Ein lange slowenische Vorrede zum Neuen Testament, ${ }^{17}$ die Katechismen sowie Articuli oli deili te prave stare vere kerszhanske [...] / Drei Christliche Confessionen $[\ldots]^{18}$ und die Slowenische Kirchenordnung. ${ }^{19}$ Zugunsten einer einheitlichen protestantischen Kirche in Innerösterreich erreichte er im Jahr 1582 die Unterschrift der Formula concordiae. ${ }^{20}$ Er unterstützte aber auch entschieden den Druck der gesamten slowenischen Bibel von Georg/Jurij Dalmatin. Die Landstände von Krain zeigten ihm ihre Anerkennung unter anderem auch dadurch, dass sie ihn bis zu seinem Tod mit 200 Gulden jährlich unterstützten.

Das erste „Geschichtsdenkmal“" wurde ihm mit der Grabrede von Jacob Andreae, einem Theologen an der Tübinger Universität gesetzt, die auch gedruckt wurde. ${ }^{21}$ Diese Grabrede wurde übersetzt und in slowenischer Sprache gedruckt. ${ }^{22}$ Andreae hob darin besonders die Predigten hervor, die von Primus Truber gehalten wurden. Ein bleibendes Denkmal ist auch das Bild der Familie Truber in der Pfarrkirche von Derendingen.

16 Rolf-Dieter Kluge: Primus Truber, Leben. Werk und Wirkung. Ein Überblick. In: Lorenz/ Schindling/Setzler (wie Anm. 3), S. 69-77; Oskar Sakrausky: Primus Truber. Deutsche Vorreden zum slowenischen und kroatischen Reformationswerk. Hg.: Institut für protestantische Kirchengeschichte Wien mit der Slovenska akademija znanosti in umetnosti Ljubljana. Wien 1989.

17 Primus Truber: Tiga Noviga Testamenta ena dolga predguuor v ti so ti nerpotrebnishi inu pridnishi artikuli oli shtuki te kerszhanske vere [...]. Ein lange Windische Vorred über das new Testament, darinn die notigesten vnd seligmachenden Hauptartickel des christlichen Glaubens, fürnemblich aber von der Rechtfertigung des Menschens sind eingefürt. Vtibini 1557; Jože Rajhma: Trubarjeva ena dolga predguvor. Ljubljana 1986.

18 Primus Truber: Articuli oli deili te prave stare vere kerszhanske [...]. Drey Christliche Confessionen, namlich Augspurgische, Wirtembergische vnd Sächsische, wie die eine dem Großmächtigsten Römischen Keiser Carolo dem fünfften, etc. hochloblicher Gedächtnuß, im 1530. Jahr, vnd die anderen zwo dem Concilio zu Trient Anno 1552, von etlichen von Gott erleüchten, Chur. Fürsten, Stett vnd Theologen überantwort, auß Latein vnd Teütsch, in diß Windisch Buch zusamen gezogen. V Tibingi 1562.

19 Primus Truber: Slovenska cerkovna ordninga. Tübingen 1564.

20 Mirko Rupel: Primož Trubar in Formula concordiae. In: Mirko Rupel (uredil): Drugi Trubarjev zbornik. Ob štiristoletnici slovenske knjige. Ljubljana 1952, S. 65-112.

21 Jakob Andreae: Christliche Leich Predig, Bey der Begräbnus des Erwürdigen vnd Hochgelerten Herrn, Primus Trubern [...]. Tübingen 1586.

22 Jakob Andreae / Mathias Trost: Ena lepa inv pridna pridiga, per pogrebi tiga vreidniga inu vissoku vuzheniga Gospud Primosha Trvberia rainciga, dershana od Gospud Iakoba Andrea Doctoria, Tibinskiga Probsta, inu is Nemshkiga iesika v slovenski tolmazhena. Tvbingae 1588. 
Truber ging in die Geschichte nicht nur als Reformator ein, sondern auch als eine zentrale Persönlichkeit der slowenischen und der innerösterreichischen Reformation sowie des kroatischen protestantischen Druckes. Nicht zuletzt war Truber der erste innerösterreichische Prediger, den der innerösterreichische Herrscher aus dem Lande verwiesen hat.

Wie hat Primus Truber sich selbst wahrgenommen? In erster Linie als Prediger und Diener der Kirche: windischer vnd teutscher prediger, ${ }^{23}$ Pfarherr (Derendingen), ${ }^{24}$ Caplan, ${ }^{25} 1553$ Prediger (Kempten), 1555 ecclesiae Minister und Primus Truber - pastor, ${ }^{26}$ im Brief an König Maximilian 1560 Prediger, ${ }^{27} 1561$ im Brief an den Laibacher Bischof Seebach: Primus Truber, einer ersamben landschafft jn Chrain berueffter Prediger, ${ }^{28} 1561$ im Brief an König Maximilian aus Urach: E. khön. Mt. Vnderthänigster trewer caplan, pfarrer daselbst. ${ }^{29}$ Weder in seiner Zeit in Laibach (1562-1565) noch später, hat er sich Superintendent genannt.

Trubers Selbstwahrnehmung illustriert am besten seine Antwort auf Bischof Seebachs Frage, die Peter Hitzinger publiziert hat: Warum er Primus als ein vertriebener Häreticus und Schismaticus dem Landt gewiechen, und wider ohn. Kön khays. Auftrag und mein als Ordinarii sich wider ins Landt begeben, und inn Purger Spital zu Laibach ohn mein Wissen zu prediciren und alle Sacramente zu administriren unterwunden, wer ihme Gwalt geben? Truber antwortete: Er sey kein Hereticus noch Schismaticus, sundern gueter Christ, er lernt und thuet, wie Christus gethan hat. Daß er aber aus den Landt gewiechen, das habe er auß dem befelch Christi und der Apostel gethan; so Christus der Herr spricht: so sie in einer Stadt verfolgen, ziehet in die andere, bis besser wirdt, und sich das Volkh erkhennen thet. Daß er herin wieder khumen ist in das Landt, das habe er nicht für sich selbst gethan, sundern ihn die ersame Landtschafft in Wien gebeten, aus Tibingen her bewegt. Er soll Inen das recht Wort und klare Wort Gottes predigen, laut der Augspurgischen Confession, darauf ihme die ersame Landschafft und Purgschaft das Spital zu predigen angeweist, und die Sacramenta zu administriren befolchen. ${ }^{30}$

23 Sakrausky: (wie Anm. 16): Edni kratki razumni nauci (glagol) 1562, S. 242.

24 Ebd., Ta celi Catehismus, 1567, S. 365.

25 Ebd., Ta celi novi, 1582, S. 431.

26 Rajhman (wie Anm. 2), S. 24, 27.

27 Ebd., S. 40.

28 Ebd., S. 87.

29 Ebd., S. 94.

30 Peter Hitzinger: Beiträge zur Geschichte der Reformation in Krain. In: Mittheilungen des historischen Vereins für Krain 19 (1864), S. 1-8, hier S. 6. 


\section{Der staatliche Rahmen und die kirchlichen Verhältnisse zu Trubers Zeit}

Trubers Heimat Krain gehörte in den Rahmen des Heiligen Römischen Reichs. Truber nannte es Sveti Rayh (Heiliges Reich). Sie bildete gemeinsam mit den Ländern Kärnten, Steiermark, Görz und der Stadt Triest die Einheit Innerösterreich, deren Landesfürsten die Habsburger waren - zu Trubers Lebzeiten Kaiser Maximilian I., Kaiser Ferdinand I. und Erzherzog Karl II. Das slowenische Landesgebiet am Rand des Reichs litt unter den Türken wegen deren Raubzügen und der Verteidigungssteuern. Kriege gab es auch mit der Republik Venedig (1508 und 1516). Der wichtigste Feldherr Habsburgs in diesen Kriegen war der Laibacher Bischof, Humanist und Diplomat Christoph Rauber.

Der Begriff ,Windisch“, den Truber in deutscher Sprache, wie damals üblich, für slowenische Gebiete verwendete, wurde auch geographisch bekannt, z.B. auf der Ortelius-Karte: Windische Mark für das Unterkrain, Windischpuchl/Windischen Bühel/Slovenske gorice für die slowenische Landschaft zwischen den Flüssen Drau und Mur, aber auch Windischland für das kroatische Slawonien. In seinen deutschen Texten und Textteilen hat Truber nie das Wort „slowenisch“ benützt, sondern das deutsche Wort ,windisch“.

Trubers Heimat war geistig nicht so tot und unwissend, ${ }^{31}$ wie sie Truber schwarzseherisch darstellte. ${ }^{32}$ Stammten doch aus dessen Nicht-Adels-Kreisen zahlreiche Humanisten in Wien, wie Thomas de Cilia, der Erzieher des späteren Kaisers Maximilian I., 1491-96 Bischof in Konstanz, ${ }^{33}$ und Michael Tiffernus, ${ }^{34}$ humanistischer Erzieher und späterer Berater des Herzogs Christoph von Württemberg. Auch den einfachen Slowenen war der deutsche Raum nicht unbekannt. Köln, Aachen und Altötting waren bei den Slowenen beliebte Wallfahrtsorte, die sie in großen Zügen alle sieben Jahre aufsuchten. ${ }^{35}$ Die Freisinger Bischöfe waren als Herren von Bischoflack/Škofja Loka ein Bindeglied zwischen dem deutschen und dem slowenischen Raum. ${ }^{36}$

31 Rajhman (wie Anm. 2), S. 199: Brief an Adam Bohorič 1. August 1565: Humanissime uir. Non dubitamus te perspicere ac non semel deplorre tristem hanc harum regionum patrae nostrae calamitatem ac barbariem: uptote, in quibus bonarum artium humaniorumque studiorum contemptus et negletctio passim iam turpiter dominatur.

32 Annamaria Lesigang-Bruckmüller: Der lateinische Brief Primus Trubers an Adam Bohorič im Kontext humanistischer Briefliteratur. In: Vincenc Rajšp / Karl W. Schwarz / Bogusław Dybaś / Christian Gastgeber (Hg): Die Reformation in Mitteleuropa. Beiträge anlässlich des 500. Geburtstages von Primus Truber. Wien, Ljubljana 2011, S. 313-323.

33 Primož Simoniti: Humanismus bei den Slovenen. Slovenische Humanisten bis zur Mitte des 16. Jahrhunderts. Hg. und bearb. von Marija Wakounig, übersetzt von Jože Wakounig. Wien 2008, S. 181.

34 Franz Brendle: Michael Tiffernus, (1488-1555). Humanistischer Lehrer, politischer Ratgeber und Vertrauter Herzog Christophs von Württemberg. In: Lorenz/Schindling/Setzler (wie Anm. 3), S. 229-245.

35 Jože Stabej: Die alten Wallfahrten der Slowenen an den Rhein. In: Zeitschrift des Aachner Geschichtsvereins 78 (1967), S. 97-160.

36 Pavle Blaznik: Škofja Loka in loško gospostvo (973-1803). Škofja Loka 1973. 


\section{Kirchenorganisation}

Der Großteil des slowenischen Gebiets gehörte, was die kirchliche Verwaltung anbelangt, in den Rahmen zweier alter Bistümer, des Patriarchats von Aquileja und des Salzburger Erzbistums, die Grenze zwischen den beiden wurde von Kaiser Karl dem Großen im Jahr 811 entlang des Flusses Drau festlegt.

Die Macht der Päpste war nicht zu spüren, mit dem Gebiet war nur Pius II., der Humanist Aeneas Silvius Piccolomini, ein Freund der Habsburger, näher verbunden. Er war zuerst Bischof in Triest (1447), 1453 Inhaber der Pfarre St. Pankratius in Altenmarkt/Stari trg bei Windisch Graz/Slovenj Gradec und bestätigte als Papst die Gründung des Bistums Laibach (1462), überließ aber das Recht der Ernennung der Bischöfe den Habsburgern. Eine bedeutende Rolle spielten noch die Zisterzienser-Klöster Sittich/Stična und Landstrass/Kostanjevica.

Auch andere Bischöfe, der Bischof von Brixen wegen seines Besitzes in Veldes/ Bled und die Freisinger mit ihrem Besitz in Bischoflack, übten im Land einen Einfluss aus. In diesem Raum gab es keine zentrale Kirchenautorität.

Eine zentrale Autorität war nur der Landesfürst, der ein vom Papst bestätigtes Recht auf Ausübung von Visitationen hatte, die zu jener Zeit „,im Kontext mit dem Finanzbedarf des Landesfürsten und der Osmanen-Abwehr zu sehen waren, wobei zu bedenken ist, dass die Landesklöster die Finanzreserve des Landesfürsten und Pfarren die Grundlagen für das Aufgebot zur Landesverteidigung bildeten. ${ }^{37}$

\section{Primus Truber und Johannes Brenz}

Hier und heute scheint es mir richtig zu sein, auf das Verhältnis zwischen Primus Truber und Johannes Brenz, dem Reformator aus Schwäbisch Hall, aufmerksam zu machen, wo, wie wir heute wissen, die ersten beiden slowenischen Bücher gedruckt wurden - was Truber übrigens zeitlebens geheim hielt.

Aus der ziemlich umfangreichen Korrespondenz von Primus Truber ist kein einziger Brief zwischen den beiden bekannt. Trotzdem wusste Truber über Brenz bereits in Laibach Bescheid, da ihm doch Bischof Franz Katzianer in seinem Testament die Werke von Brenz vermachte..$^{38}$

Brenz' Katechismen bildeten die Unterlage für Trubers Katechismen. Für seine ersten beiden Bücher Catechismus und Abecedarium verwendete Truber Brenz' kleinen Katechismus ${ }^{39}$ und übernahm die Brenzsche Methode der Fragen und Antworten. ${ }^{40}$ Von Brenz übernahm er die Idee, auch Frauen und Mütter in den

37 Kohler (wie Anm. 1), S. 193.

38 Rupel/Saria (wie Anm. 5), S. 46.

39 Ebd., S. 86.

40 Jože Rajhman: Prva slovenska knjiga v luči teoloških, literarno-zgodovinskih, jezikovnih in zgodovinskih raziskav. Ljubljana 1977, S. 99. 
Unterricht des Katechismus einzubeziehen. Truber erwähnt Brenz in seinem Katechismus 1567, als er die Bedeutung des Katechismus fürs Lernen betont. Im Katechismus aus dem Jahr 1575 erwähnt er ihn bereits im deutschsprachigen Titel Catechismus mit des Herren Brentij und M. C. Vischers Außlegung. Die Tatsache, dass er Brenz bereits im Titel nannte, und zwar in einer Arbeit, die in erster Linie zur Verteidigung der evangelischen Kirche in der Heimat bestimmt war, zeugt von der großen Bedeutung, die Brenz in Trubers Augen hatte. Im Letzten Teil des Neuen Testaments 1577 schreibt er, dass er Vorschläge von Brenz für seine Kommentare verwendet. Eine Predigt von Brenz wird auch von Georg Dalmatin im Vorwort zu Der gantze Passion 1576 als Vorlage erwähnt. ${ }^{41}$ Dass Truber Brenz außerordentlich schätzte, zeigt bereits die Erwähnung in den Articuli oli deili, Brenz habe als Theologe am Konzil in Trient teilgenommen. Weiters erwähnt Truber Brenz, als er den Ständen über dessen Glaubensgespräche in Frankreich berichtet, wo neben dem württembergischen Fürsten auch Brenz anwesend war. ${ }^{42}$

Brenz spielte auch eine bedeutende Rolle bei der Frage, ob Truber der Einladung der Krainer Landstände, als Prediger nach Laibach zu kommen, und zwar gegen den Willen des Kaisers, Folge leisten solle. Johannes Brenz und andere geistliche Berater des Herzogs waren der Meinung, dass Truber in Laibach in Glaubensangelegenheiten ohne das Wissen des Königs Maximilian nichts unternehmen solle. ${ }^{43}$ Dass Truber und Brenz auch im direkten Kontakt waren, zeigt Trubers Briefstelle Vnd der Herr Brenzius saget zu mir in einem Brief an Heinrich Bullinger. ${ }^{44}$ Trotzdem kam es zu einem peinlichen Streit anlässlich des Druckes der Kirchenordnung, wonach Truber hinsichtlich der Streitigkeiten zwischen Andreae und Brenz sowie den Zwinglianern im Brief an Nikolaus Graveneck diesen Streit bedauerte und zufrieden berichtete, dass es solche Streitigkeiten in Laibach nicht gebe. ${ }^{45}$ Dass Brenz einen guten Einblick in das Geschehen der evangelischen Kirche in Krain hatte, wird uns von Truber in einem Brief im Zusammenhang mit der Suche nach einem neuen Prediger in Krain im Jahr 1568 berichtet. ${ }^{46}$ Brenz war für Primus Truber und seine reformatorische Tätigkeit bei den Slowenen eine sehr wichtige Person, trotzdem wissen wir nicht, welche Rolle er bei dem Druck der ersten slowenischen Bücher in Schwäbisch Hall spielte.

41 Sakrausky (wie Anm. 16), S. 542, 545.

42 Rajhman (wie Anm. 2), S. 108: Joštu Gallenbergu, deželnemu oskrbniku in odbornikom kranjskim, Urach 11. aprila 1562.

43 Rupel/Saria (wie Anm. 5), S. 129.

44 Rajhman (wie Anm. 2), S. 30: Im Brief an Heinrich Bullinger, Kempten 10.7.1557.

45 Rupel/Saria (wie Anm. 5), S. 204.

46 Rajhman (wie Anm. 2), S. 202. 


\section{Die Wahrnehmung Primus Trubers zu Ende des 16. und im 17. Jahrhundert}

Die Reformation erreichte in den innerösterreichischen Ländern ihren Höhepunkt mit der Brucker Pazifikation 1578. „Die Pazifikation für den Adel und die Bürger in den privilegierten Städten schufen die Voraussetzung, unter der die innere Strukturierung des evangelischen Kirchenwesens einsetzen konnte. ${ }^{647}$ Doch wurde bei der darauffolgenden konkreten Organisation der Evangelischen Kirche in Innerösterreich Truber nicht einbezogen, es wurde nicht einmal seine Kirchenordnung (Cerkovna ordninga) berücksichtigt, und auch die Position der slowenischen Sprache oder der „Slowenischen Kirche“ wurde nicht festgelegt. Gleichzeitig verschärfte Erzherzog Karl II. die Abwehr der katholischen Seite „mit der Beschränkung des evangelischen Religionsexerzitiums auf die Herren und Ritter, die Entfernung der Prädikanten aus den nichtprivilegierten landesfürstlichen Städten und Märkten und das Verbot des Auslaufens der Stadt- und Marktbewohner zu den Predigern auf den adeligen Schlössern“. ${ }^{48}$ Der Landesfürst, Kaiser Ferdinand I., und sein Sohn Karl II. haben in der zweiten Hälfte des 16. Jahrhunderts, parallel zu den protestantischen Ständen im Reich, die Macht in der Kirche als obrister advocat der kirchen weiter ausgebaut. So konnten die Konvente ihre Vorsteher (Äbte) seit 1561 nicht mehr ohne fürstliche Aufsicht wählen. Die Wahl des Abtes im Zisterzienserkloster in Sittich musste 1566 wiederholt werden, weil sie ohne Wissen des Landesfürsten Karl II. durchgeführt worden war. Erst als dieser sicher war, dass der Kandidat der eine Klosterpfarre innehatte, nicht verheiratet und katholisch war, konnte die Wahl wiederholt werden, wobei wieder derselbe Kandidat gewählt wurde. ${ }^{49}$ Karl II. hat die Beschlüsse der Diözese in Udine 1583 (anwesend waren auch die Äbte aus Sittich und Landstrass) für sein Territorium nicht anerkannt, er wollte ein neues Bistum in Görz errichten, scheiterte aber an dem Widerstand des Patriarchen.

Nach dem Jahr 1600 hat Erzherzog Ferdinand in Innerösterreich eine gründliche Rekatholisierung durchgeführt und die Protestanten gezwungen, zwischen der Annahme des katholischen Glaubens und der Aussiedlung zu wählen, was in Übereinstimmung mit den Prinzipien des Augsburger Religionsfriedens war.

Die erste Erwähnung Trubers und der slowenischen Protestanten findet sich im Buch Gründlicher Gegen Bericht Auff Den falschen Bericht ${ }^{50}$ aus dem Jahr 1606, wo Truber gemeinsam mit dem Kanoniker Paul Wiener als von der katholischen Religion abgefallen bezeichnet wurde. Erinnerung an Primus Truber be-

47 Karl Heinz Frankl: Die katholische Konfessionalisierng in Kärnten bis 1628. In: Carinthia 190 (2000), S. 227-238.

48 Ebd., S. 231.

49 Jože Mlinarič: Stiška opatija 1136-1784. Novo mesto 1995, S. 357.

50 Johannes Rosolenz: Gründlicher Gegenbericht Auff Den falschen Bericht [...] Davidis Rungij Von der Tyranischen Bäpstischen Vervolgung deß H. Evangelij in Steyermarckt (etc). Grätz 1606, S. 131. 
wahrte auch Hermanus Fabronius Mosemann in seinem Werk „Newe Summarische Welthistoria“" aus dem Jahr 1625, das Truber als Übersetzer der slowenischen und kroatischen Bücher darstellt, mit dem wichtigen Beisatz, dass die noch vorhanden sind: Hans Ungenad Freiherr zu Sonneck in Crobaten / zur Zeit der Augsburgischen Confession / hat die Bibel und andere Bücher zu Aurach im Land zu Wittenberg vertieren lassen / darzu er drey Windische Gelehrten gebraucht hat. Einer hieß Primus Truber, der ander Antonus Dalmata, der dritte Stephanus Consul [...]. Wer is begehrt / kan die Bücher auch zu Cassel in Fürstlicher Bibliotheca zusehen bekommen. So sind auch einzeln Exemplaria in Windischland kommen / und bei den Evngelischen Landherrn zu finden. ${ }^{51}$

Die erste umfangreichere Darstellung Trubers und des Protestantismus in Krain veröffentlichte jedoch Johann Weichard Valvasor in seinem Werk Die Ehre deß Herzogthums Krain, herausgegeben 1689 in Nürnberg. Er stellte Primus Truber als jemanden dar, der in Krain als Schriftsteller tätig war, als jemanden, der die Lehre Luthers annahm, weswegen er das Land Krain verließ und „ins Reich“ ging, wo er als ein gelehrter Mann von der Stadt Kempten als Prediger aufgenommen wurde. Valvasor stellte Trubers Werke vor und betonte: dieser hat also den Anfang gemacht der Erfindung / mit Lateinischen Littern Crainerisch zu schreiben / und mit dergleichen Buchstaben auch drucken zu lassen. Von Valvasor konnte man erfahren, daß mehrerwehnte Truber / durch Cooperierung Doctoris Jacobi Andreae, Probstens / Canzlers / und Superintendentis der Kirchen und hohen Shul zu Tuebingen / die Formulam Concordieae auflegen lies. ${ }^{52}$ Weiters unterstrich er, dass er die deutsche Postille Dr. Martin Luthers auf Sclavonisch oder Crainerisch übersetzte, die die Löbliche Landschaft in Crain dann auf eigene Kosten in Tübingen drucken ließ, und er betonte weiter, dass die Drucke von dem Rektor der evangelischen Schule der Landstände in Klagenfurt (Collegium sapientiae et pietatis) Hieronimus Megiser nach Laibach gebracht wurden. Valvasor erwähnt auch die Druckerei in Tübingen, dabei beruft er sich auf ein Werk des Hermann Fabronius Mosemann. Trubers Lebenslauf stellte Valvasor mit einem (bisher allerdings unbekannt gebliebenen) Truber-Brief dar: Im Jahr 1586 / als in dem letzten Lebens=Jahr des Trubers / hat derselbe denen Herren Verordneten in Crain den letzten Brieff geschrieben / auch denselben eigenhändig unterschrieben: Primus Truber / gewesener / ordentlich beruffener / praesentiirter und confirmirter Thumherr zu Laibach / Pfarrer zu Lack / bey Ratschach zu Tüffer / und in S. Barthelmer Felde / Caplan bey S. Maximilian zu Cilly / Windischer Prediger zu Triest und nach der ersten Verfolgung Prediger zu Rotenburg an der Tauber / Pfarrer zu Kempten / und Aurach / nachmals Prediger der Erl. Loebl. Landsch. In Crain / und in der Grafschafft Goerz zu

51 Hermannus Fabronius Mosemannus: Geographia historica. Newe summarische Welthistoria, oder Beschreibung aller Kayserthumb, Königreiche, Fürstenthumb und Völker Heutiges Tages auff Erden. Gedruckt bei Wolfgang Ketzel, Schmalkalden 1625.

52 Johann Weikhard von Valvasor: Die Ehre deß Herzogthums Krain. Buch VI. Laibach 1689, S. 346 . 
Rubia; und / nach der andern Verfolgung / Pfarrer zu Lauffen / und jetzund zu Derendingen / bey Tuebingen. Es gedenkt auch Martinus Zeiler / in der Epistolischen Schatzkammer daß dieser Truber / im Jahr 1586 gestorben sey. ${ }^{53}$

$\mathrm{Zu}$ den protestantischen Schriftstellern zählt Valvasor noch Christoph Spindler und dessen gedruckte Leichpredig für Herward von Auersperg, der im Jahr 1575 in der Schlacht bei Budatschki in Kroatien gegen die Türken gefallen ist, sowie die erste slowenische Grammatik von Adam Bohorič Arcticae horulae [...] von der er meinte: Diß Buch / welches gleichsam fuer eine Grammatic dienet / ist mit grossem muehsamen Fleiß gemacht [...] In der Vorrede / ist viel enthalten / so den Slavis (oder Sclavoniern) zu Ruhm und Ehren gesetzt. ${ }^{54}$

Große Aufmerksamkeit widmete Valvasor auch Georg Dalmatin, dem Übersetzer der gesamten Bibel in die slowenische Sprache, deren Druck in Laibach von Erzherzog Karl verboten wurde. Die innerösterreichischen Stände entschieden sich für den Druck in Wittenberg, wo die Bibel dann zu Neujahr 1584 gedruckt wurde. Der Druck kostete 8.000 Gulden, dazu wurden von den steirischen Ständen 1.000, von den Kärntner 900 und von den Krainer Ständen 6.100 Gulden beigesteuert. Valvasor betonte, dass Übersetzung und Druck von den Protestanten organisiert und finanziert wurden, und er betont die hohe sprachliche und theologische Kompetenz der Kommission. Er betont auch, dass die Bibel noch taeglich / in Crain / von denen Geistlichen / welche dessen Erlaubniß haben / gebraucht wird; weil wir keine andre Windische haben. ${ }^{55}$ Die Darstellung der slowenischen Reformation und Trubers in der „Ehre“ durch Valvasor und von seinem Mitautor und Korrektor Erasmus Francisci blieb ein Jahrhundert lang die einzige Quelle für die Wahrnehmung Primus Trubers. Sie kann als ein Produkt der Zusammenarbeit eines Katholiken und eines Protestanten in einer konfessionellen Zeit betrachtet werden.

\section{Truber in der Zeit der Josephinischen Reformen}

Zur neuen Truber-Wahrnehmung trugen mittelbar die Reformen von Joseph II. bei. Die „Äussere Kirchenverfassung“ Innerösterreichs blieb zur Zeit der Gegenreformation unverändert. Die Klöster erlebten im 17. Jahrhundert einen Aufschwung. Neue Impulse kamen vor allem von zwei neuen Orden, und zwar von den Jesuiten im Schulwesen, mit Kollegien in allen Landeshauptstädten und ihren Volksmissionen, sowie von den Kapuzinern, die eine neue Art des Predigens brachten. Obwohl die Orden nicht unmittelbar die Vernichtung des Protestantismus herbeiführten - dies tat der Landesfürst selbst, der auch beide Orden ins Land holte -, verwirklichte sich Trubers böse Ahnung, dass die Jesuiten mit der

53 Ebd.

54 Ebd., S. 347.

55 Ebd., S. 349. 
Verwendung der Volkssprache im Katechismus und in den Predigten für den Protestantismus eine besondere Gefahr darstellten.

Kaiser Joseph II. änderte diesen Zustand gründlich. Der Jesuitenorden war schon im Jahr 1773 von seiner Mutter Maria Theresia aufgehoben worden. Mit dem Toleranzpatent 1781 tat Joseph II. den ersten Schritt in Richtung einer vollen religiösen Akzeptanz der Protestanten des Augsburgischen und Helvetischen Bekenntnisses in den habsburgischen Ländern. In der katholischen Kirche führte er Reformen durch, die für eine erfolgreiche Organisation der protestantischen Kirche im 16. Jahrhundert notwendig gewesen wären.

Die von Joseph neu eingeführten Diözesangrenzen stimmten nun grundsätzlich mit den Landesgrenzen überein. Eine außerordentliche Bedeutung widmete er der jeweiligen Volksprache, nach Möglichkeit war das eines der Kriterien für die Abgrenzung der Bistümer. Die Volkssprache als Kriterium für die Diözesangrenzziehung wurde aber nur für die Slowenen in der Steiermark berücksichtigt. Doch auch dort wurde erst 1859 die neue Grenze zwischen der „deutschen“ Diözese Graz und der „windischen“ Diözese Lavant (Marburg) verwirklicht. Joseph II. schaffte die meisten Klöster ab und führte deren Vermögen dem neugegründeten Studien- und Religionsfonds zu, womit unter anderem der Lohnausgleich für Priester in den neugegründeten Pfarren finanziert wurde. Er schloss Wallfahrtskirchen, wie z. B. jene zum Heiligen Berg bei Görz/Sveta gora pri Gorici, gegen die Primus Truber mit Nachdruck gepredigt hatte, und insbesondere verbot Joseph II. Wallfahrten. Das kirchliche Vermögen und die Tätigkeit der Bischöfe und Priester wurden komplett unter die Aufsicht des Monarchen gestellt, wodurch die Geistlichen praktisch zu Staatsbeamten wurden. Ebenso wurde die Ausbildung von Priestern, Bischöfen und Pfarrern genau festgelegt und kontrolliert.

Bei der Reform hatte der Kaiser zahlreiche Bischöfe auf seiner Seite, für Innerösterreich waren die wichtigsten Bischof Josef Franz Anton Graf von Auersperg in Klagenfurt und Bischof Johann Karl Reichsgraf von Herberstein in Laibach. Trubers Wunsch, dass man das Vermögen, das die Herrscher für Pfarren, Bistümer, Domkapitel und Klöster stifteten, besser für Schüler, Lehrer und Prediger verwenden sollte, ging erst jetzt, im 18. Jahrhundert in Erfüllung, wenn auch nicht mehr in seiner Kirche. Herberstein setzte sich für die Verwendung der slowenischen Sprache in der Kirche ein, gab einen Katechismus in slowenischer Sprache heraus, organisierte eine neue Übersetzung der Heiligen Schrift und wurde ein Befürworter der religiösen Toleranz weswegen von den Kritikern als Lutheraner apostrophiert. ${ }^{56}$

Nach dem Toleranzpatent wurde die protestantische Gemeinde in Triest wieder zum Leben erweckt, ${ }^{57}$ und mit ihr bei den Slowenen auch die protestantische

56 Herberstein Karl Janez. In: Slovenski biografski Lekskon. Ljubljana 1925-1932, S. 312.

57 Herbert Patzelt: Evangelisches Leben am Golf von Triest. Geschichte der evangelischen Gemeinde in Triest mit Abbazia, Görz, Fiume und Pola. München 1999, S. 48. 
Gemeinde Agoritschach/Zagoriče in Kärnten, die als krypto-protestantisch überlebte. ${ }^{58}$ Sie bewahrte die ersten slowenischen protestantischen Bücher auf, wurde aber im Laufe des 19. Jahrhunderts ,eingedeutscht“.

\section{Wissenschaftliche Wahrnehmung Primus Trubers im 18. und 19. Jahrhundert}

Die josephinischen Reformen brachten im slowenischsprachigen Gebiet im österreichischen Teil der Habsburgermonarchie eine Verschiebung in zwei Bereichen, die übrigens erst in der 2. Hälfte des 19. Jahrhunderts zum Tragen kam. Das Entstehen neuer evangelischer Gemeinden einerseits und andererseits die Durchsetzung der slowenischen Sprache im öffentlichen Gebrauch. Die Träger dieser beiden - gegenläufigen - Entwicklungen sollten in der Folge zu den Hauptkonkurrenten und Akteuren der politischen Landschaft werden.

Nach dem endgültigen Verbot des Protestantismus Ende des 16. Jahrhunderts blieben folgende ihrer Texte in slowenischer Sprache weiter in Gebrauch: Georg Dalmatins Bibel, Bohorič Grammatik (Neuauflage im Jahr 1715 ohne Nennung seines Namens), wurde im Jahr 1744 von den slowenischen Jesuiten in Klagenfurt in deutscher Übersetzung herausgegeben. Im Jahr 1744 erschien eine von den Jesuiten in Klagenfurt veranstaltete Neuauflage von Hieronimus Megisers Wörterbuch Dictionarium quatuor linguarum in den Sprachen Deutsch, Lateinisch, Slowenisch und Italienisch. ${ }^{59}$

Eine neue Epoche des Interesses an Truber und den slowenischen Protestanten brach im Jahr 1799 mit Christoph Schnurrer und seinem Buch „Slavischer Bücherdruck" an. ${ }^{60}$ Es handelt sich um das erste Werk über die slawische Druckerei in Urach - auf der Basis eines umfangreichen Materials, das im Archiv der Universität in Tübingen aufbewahrt wird. Auf dessen Grundlage wird die Tätigkeit Primus Trubers, Peter Paul Vergerius' und Hans Ungnads beschrieben. ${ }^{61} \mathrm{Im}$ 19. Jahrhundert wird Wien mit der Habsburgischen Hofbibliothek, heute Österreichische Nationalbibliothek, mit ihrer ,weltweit zweitgrößten Sammlung von Originalen südslawischer Reformationsschriften“"62 auch ein Mittelpunkt des wissenschaftlichen Interesses an der slowenischen Reformation und Primus Tru-

58 Karl W. Schwarz: Agoritschach/Zagoriče - eine evangelische Gemeinde im gemischtsprachigen Südkärnten. In: Carinthia I. Zeitschrift für geschichtliche Landeskunde von Kärnten 198 (2008), S. 333-353.

59 Hieronimus Megiser: Dictionarium quatuor linguarum: Videlicet Germanicae, Latinae, Illyricae (quae vulgo sclavonica appelatur) \& Italicae, sive Hetruscae. Clagenfurti 1744.

60 Christian Friedrich Schnurrer: Slavischer Bücherdruck in Württemberg im 16. Jahrhundert. Tübingen 1799.

61 Mathias Murko: Die Bedeutung der Reformation für das geistige Leben der Südslaven. Prag 1927, S. 139.

62 Eva Hüttl-Hubert: Anmerkungen zu Struktur, Provenienz und Rezeption der südslawischen Protestantica in der Österreichischen Nationalbibliothek. In: Rajšp/Schwarz (wie Anm. 32), S. 40. 
ber. In der ersten Hälfte des 19. Jahrhunderts schreibt der angesehene Slawist, der als Skriptor in der Hofbibliothek tätige Bartholomäus Kopitar in seiner „Grammatik der slavischen Sprache in Krain, Kärnten und Steyermark“" ${ }^{63}$ den slowenischen Protestanten große Verdienste für die slowenische Sprache zu: „O ja! Biederer Bohoritsch! Dir und deinen Freunden hat es unsere Sprache zu danken. Truber würdigt er als konsequenten Denker und Freund der Einfachheit." ${ }^{\text {"64 }}$ Im Jahr 1814 kaufte Kopitar „,18 slowenische/kroatische Protestantica aus dem Besitz Schnurrers, die heute einen wesentlichen Bestand der Protestanticasammlung in Ljubljana bilden" ${ }^{65}$ Trubers Sprache interessierte auch den wichtigsten Slawisten in der zweiten Hälfte des 19. Jahrhunderts in Wien, den Begründer der wissenschaftlichen Slawistik und ihren bedeutendsten Vertreter im 19. Jahrhundert, Franz von Miklosich (Fran Miklošič) und andere Sprachforscher. 1874 gab der Skriptor der Hofbibliothek, der Kroate Ivan Kostrenčić „Urkundliche Beiträge der protestantischen Literatur der Südslaven in den Jahren 1559-1565" heraus, worin er Material aus dem Universitätsarchiv in Tübingen veröffentlichte. In diese Reihe gehört auch Fran Kidrič, ebenso Skriptor der Wiener Hofbibliothek, der mit der literarisch-kulturhistorisch-philologischen Untersuchung „Die protestantische Kirchenordnung der Slovenen im XVI. Jahrhundert" ${ }^{* 66}$ eine vorbildliche Studie schuf und der im Jahr 1920 den Schwerpunkt der wissenschaftlichen Erforschung der slowenischen protestantischen Literatur und Sprache auf die neu gegründete Universität in Ljubljana übertrug.

\section{Die wichtige Wende des Jahres 1848}

Eine wichtige Wende für die Wahrnehmung von Truber markiert das Revolutionsjahr 1848. Wie die Protestanten angesichts des Todes von Kaiser Franz Joseph schrieben, stammten ihre Rechte aus der 48er Revolution. ${ }^{67}$ Auf die Revolution geht auch das Recht zum Gebrauch des Slowenischen als Amtssprache zurück, da doch die slowenische Sprache im Jahr 1849 zu den zehn Sprachen gezählt wurde, in denen das allgemeine „Reichsgesetz= und Regierungsblatt für das Kaiserthum Österreich“ erschien. Damit ist die slowenische Sprache zu einer einheitlichen Schriftsprache sowie zur Unterlage und Grundlage für die Verwirklichung der nationalen Einheit geworden. Dies schuf ein neues Verhältnis

63 Bartholomäus Kopitar: Gramatik der slavischen Sprache in Krain, Kärnten und Steyermark. Laibach 1808.

64 Murko (wie Anm. 61), S. 141.

65 Walter Lukan: Kopitars Privatbibliothek. In: Walter Lukan (Hg.): Bartolomäus (Jernej Kopitar). Neue Studien und Materialien anläßlich seines 150. Todestages. Wien 1995, S. 239. Auch in: Österreichische Osthefte 36 (1994), S. 588-705.

66 Franc Kidrič: Die protestantische Kirchenordnung der Slovenen im XVI. Jahrhundert. Eine Literarisch-Kulturhistorisch-Philologische Untersuchung. Heidelberg 1919.

67 Georg Loesche: Kaiser Franz Joseph I. und der österreichische Protestantismus (18.8.183021.11.1916). In: Jahrbuch für die Geschichte des Protestantismus in Österreich 37 (1916), S. 3-7. 
zwischen der deutschen und der slowenischen Sprache und als Folge davon auch zwischen den Deutschen und den Slowenen.

Einen interessanten Beweis zu den nicht-belasteten nationalen Anschauungen gibt uns Carl Bernhardi mit seiner Karte „Sprachkarte von Deutschland“, ${ }^{8}$ auf der die ,genaue“ deutsch-slowenische Sprachgrenze eingezeichnet ist. Als Quelle verwendete er die Daten von Pavel Josef Šafař́k, der 1842 ein Buch über die Slawische Ethnographie ${ }^{69}$ und eine Karte sämtlicher slawischer Gebiete „Slovanský Zeměvid“70 herausgegeben hat. Darauf erscheinen die Slowenen das erste Mal auf einer Karte mit dem slowenischen Wort Slovenci. Und nicht zuletzt findet sich in Heinrich Burghaus“ Physikalischem Atlas ${ }^{71}$ eine „Ethnographische Karte der österreichischen Monarchie“, die Bernhardi und Šafařík als Autoren anführt und in der die Slowenen mit ihrem slowenischen Namen als „Slowenzen“ und nicht auf Deutsch als „Windische“ angeführt werden. Die beiden Autoren - Bernhardi und Šafařík - waren Protestanten. Dies zeigt, dass die nationalen Verhältnisse im Vormärz noch keineswegs politisch belastet waren, was sich nach dem Jahre 1848 radikal änderte. Zum ersten politischen Bruch kam es anlässlich der Wahlen für das Frankfurter Parlament im Jahr 1848, die die Slowenen boykottierten, während die deutsche Seite natürlich daran teilnahm.

In ihrer nationalen Ausrichtung war die kulturelle Errungenschaft der slowenischen Protestanten für den katholischen Bischof von Lavant, Anton Martin Slomšek, annehmbar. Dieser schrieb im Jahr 1862, dass alle Völker berühmte, in der Literatur tätige Männer haben, so auch die Slowenen: „Trubar, Dalmatin, Bohorič und ihre Zeitgenossen haben unsere slovenische Sprache zum Leben erweckt, obgleich sie sich unglückseligerweise vom wahren Glauben abgewendet haben; Gott hat ihre Fehler (greške, nicht grehe: Sünden) unserem Volke in seiner unendlich weisen Vorsicht zum Guten gewendet.“72

Für die weitere Entwicklung der Beziehung zwischen Deutschen und Slowenen nach 1860 scheint mir die Bemerkung in Volker Reinhardts Buch „Luther der Ketzer" hinsichtlich der Verständnislosigkeit Roms für den deutschen Protestantismus angebracht, diese ,erklärt [sich] aus der Unfähigkeit, die Anziehungskraft der Luther'schen Lehre auf breitere Schichten nachzuvollziehen, und aus

68 Carl Bernhardi: Sprachkarte von Deutschland. Kassel 1844; Vincenc Raǰ̌p: Die Sprachengrenze zwischen der deutschen und slawischen Bevölkerung im Alpen- und Donauraum auf Karl Bernhardts Sprachkarte von Deutschland. In: Markus Heinz/Armin Hüttermann (Hg.): 16. Kartographiehistorisches Colloquium: Marbach am Neckar 2012, 27.-29. September 2012. Bonn 2016, S. 202-222, hier S. 207.

69 Pavel Josef Šafařik: Slovanský národopis. Praha 1842.

70 Pavel Josef Šafařik: Slovanský Zeměvid. V Praze, 1842.

71 Dr. Heinrich Berghaus` Physikalischer Atlas oder Sammlung von [...] Karten, auf denen die hauptsächlichsten Erscheinungen der anorganischen und organischen Natur nach ihrer geographischen Verbreitung und Vertheilung bildlich dargestellt sind. Zweiter Band. [...] 8. Ethnographie. Gotha 1848 .

72 Murko (wie Anm. 61), S. 149. 
der humanistischen Erwartung, dass sich die Kraft der Vernunft und der Sittlichkeit schließlich durchsetzen werde, verbunden mit dem Überlegenheitsgefühl gegenüber einer barbarischen Gegenwelt." "73 In der Praxis zeigte sich hingegen immer deutlicher der Unwille der Deutschliberalen, die Anziehungskraft der jungen slowenischen Nationalbewegung zu akzeptieren.

\section{Die Wahrnehmung Trubers bei den Deutschen im 19. und zu Anfang des 20. Jahrhunderts}

In der zweiten Hälfte des 19. Jahrhunderts entstanden auf dem slowenischen Sprachgebiet zahlreiche neue protestantische Gemeinden. Das ist die Zeit der Affirmation des slowenischen nationalen Erwachens und des nationalen politischen Engagements.

Doch die neuen protestantischen Gemeinden waren deutsch-orientiert, sowohl gemäß der Sprache, wie im großen Ausmaß auch hinsichtlich ihrer Mitglieder, sie beriefen sich aber auf Primus Truber als ihren Vorgänger. Die Görzer Gemeinde zählte Primus Truber zu den Initiatoren des Protestantismus in Görz, da er dort im Jahr 1564 gepredigt hatte. ${ }^{74}$ Es wurde behauptet, das Haus in Cilli/ Celje, wo ab dem Jahr 1857 protestantische Gottesdienste gehalten wurden, sei dasjenige, in dem Primus Truber gepredigt hatte. Dadurch sollte die Kontinuität betont werden. ${ }^{75}$

In der zweiten Hälfte des 19. Jahrhunderts fand ein großer Fortschritt in der Geschichtsschreibung über die Reformation im slowenischen Raum statt - um nur den aus Alten bei Dessau stammenden Theodor Elze mit seinen zahlreichen geschichtlichen Abhandlungen zu erwähnen. Sein wohl bedeutendstes Werk „Primus Trubers Briefe" ${ }^{\text {(76 }}$ enthält weit mehr als der Titel vermuten lässt, nämlich umfangreiche Erläuterungen und eine große Zahl von Briefen an Primus Truber. Desweiteren ist der Laibacher August Dimitz zu nennen, der mit seiner „Geschichte Krains ${ }^{\text {“77 }}$ den ersten umfangreichen Umriss der Reformation in Krain schrieb. Zahlreiche Beiträge kamen in den ersten fachwissenschaftlichen Zeitschriften heraus, wie z.B. in den „Mitteilungen des Historischen Vereins für Krain“ und in dem „Jahrbuch der Gesellschaft für die Geschichte des Protestantismus in Österreich“, das ab 1880 das zentrale Organ für Fragen des Protestan-

73 Volker Reinhardt: Luther der Ketzer. Rom und die Reformation. München ${ }^{32017, ~ S . ~} 162$.

74 Jahresbericht der Evangelischen Kirchengemeinde A. U. H. C. Görz 1907, S. 3.

75 Karl W. Schwarz / Gerhard May: Vom volksdeutschen Vordenker in Slowenien zum bischöflichen Wegweiser der Evangelischen Kirche in Österreich. In: Südostdeutsches Archiv 46/47 (2003/2004), S 39-63, hier S. 40; Theodor Elze: Die Einweihung der neugegründeten evangelischen Andreas Kirche in Cilli am 25. März 1857. Laibach 1857, S. 4.

76 Theodor Elze: Primus Trubers Briefe. Tübingen 1897.

77 August Dimitz: Geschichte Krains von der Ältesten Zeit bis auf das Jahr 1813. Laibach 18741876. 
tismus war. Doch alle diese Arbeiten waren in deutscher Sprache und erreichten die breitere slowenische Bevölkerung nicht. Die Slowenen hatten aber noch keine eigene Institution, wo sie qualitativ die geschichtlichen Fragen in Angriff nehmen konnten. In einer Zeit, als die Schlüsselfragen: Glaube, Kultur, Nationalität, Freiheit, Reaktion, Liberalismus, konservativer Klerikalismus waren, hat die deutschsprachige Publizistik für die Slowenen keine erwünschten Früchte erbracht.

Überdies kann man für die zweite Hälfte des 19. Jahrhunderts immer noch von einer konfessionellen Periode reden. Die liberalen Zeitschriften sind auf slowenischem Gebiet genauso wie die konservativen voll von Artikeln über Fragen der Religion und Kirche, und beide sind gleich polemisch. Zur wichtigsten Trennungslinie wird der Nationalismus der Deutschen und Slowenen, der in der Zeit des Parlamentarismus für den politischen Erfolg entscheidend war. So traten der (deutsche) Protestantismus und der (slowenische) Katholizismus als Verteidigungssysteme auf, ersterer zur Verteidigung der bedrohten Vormachtstellung der Deutschen, und der andere als Verteidiger der bedrohten Nationalität der Slowenen und als Schutz vor ihrer Germanisierung.

Ein interessantes Faktum in der Akzeptanz der Reformation in der zweiten Hälfte des 19. Jahrhunderts ist zweifellos das Buch „Primus Truber, der Reformator Krains“ des aus Hamburg stammenden Wilhelm Sillems. ${ }^{78}$ Das Buch wurde in der slowenischen Geschichtsschreibung jedoch bislang nicht berücksichtigt. Darin wird die deutsche Kultur stark betont: „Mit der Einführung der Reformation [...] war ein großartiger Anfang - das geistige, nationale Leben des windischen Volkes zu heben; eine nationale Literatur wurde durch die Reformation begründet, und so widersprechend es auch erscheinen mag, eine enge Verbindung mit Deutschland war hergestellt worden durch die Gemeinsamkeit der kirchlich=religiösen Interessen. Und endlich waren jene krainische Reformatoren darauf bedacht, über ihr Vaterland hinaus den Südslaven serbischen Stammes ähnliche, geistige und geistliche Güter zu vermitteln, wie sie aus Deutschland durch das neu erwachte, religiöse, kirchliche Leben empfangen haben. “79

Dabei führt Sillem eine neue Verständnisweise ein: den Begriff „Deutschland“, der mit Trubers Teutschen Länder nicht gleichbedeutend war. Truber lebte und wirkte im Heiligen Römischen Reich, dessen Grenzen er nie überschritten hat. Er war nie in der Republik Venedig und auch nie im Königreich Ungarn. Sillems Kultur(verständnis) wiederum betraf nicht das 16., sondern das 19. Jahrhundert. Die Kultur des 16. Jahrhunderts basierte auf einer einheitlichen kulturellen und kirchlichen Entwicklung, die Kultur des 19. Jahrhunderts basierte aber auf auseinanderdriftenden konfessionellen und v. a. nationalen Entwicklungen. Und die wurden, nach der Berliner Tageszeitung ,Zukunft“" vom „Laibacher Tagblatt“ im 
Aufsatz „Über die Stellung der Deutschen in Oesterreich“ zusammenfassend zitiert: „Die Deutschen sind die Träger der Aufklärung und der Freiheit. Die katholische Geistlichkeit fühlt sich unter diesen Verhältnissen bedroht. “80 Und über die politischen Parteien im Land Krain schreibt das deutschliberale „Laibacher Tagblatt“: „Das Deutschtum ist nebenbei auch deswegen verhasst, weil es, wie sie sagen, das Luthertum, den reformatorischen Geist in sich schließt. Der Nationale (der Slowene) schwärmt für die Geistlichkeit, und vertritt die Reaktion“. 81 Hinsichtlich der slowenischen grundlegenden Forderungen nach der Verwendung der slowenischen Sprache in Schulen und Ämtern sowie eines vereinten Slowenien berief sich das „Laibacher Tagblatt“ auf die „Augsburger Allgemeine Zeitung“. Unter dem Titel „Slovenismus und Deutschthum“ ist zu lesen: „Forderung der Herstellung eines Königreiches Slovenien, die Einführung der slovenischen Sprache in Schule und Amt, mit einem Worte, die absolute Herrschaft des lichtscheuen, kulturfeindlichen ungeschlachten Slovenismus über die deutsche Bildung, Aufklärung, [...], sollen wir unsere Schulen aufgeben oder unsere Kinder in halbbarbarischen Idiomen unterrichten lassen?" 82

Diese Anschauungen waren aber im Grunde nicht die Folge der Beziehungen zwischen den alten, autochthonen Deutschen und Slowenen, sondern wurden sehr wohl von den ,neuen“ Protestanten, importiert und verbreitet.

Prediger der neuen protestantischen Gemeinden stammten vorwiegend aus Deutschland, z. B. in Laibach: 1. Theodor Elze, 1851-1865, geboren am 17. Juli 1823 in Alten bei Dessau; 2. Otto Schack, 1866-1880, stammte aus Hessen; 3. August Knieszner, 1881-1892, stammte aus Ungarn; 4. Hans Jaquemar 18931905 (Herkunft unbekannt); 5. Dr. Ottmar Hegemann, 1906-1917, (geboren in Mannheim, vor Laibach wirkte er in der deutsch-böhmischen Stadt Haida/Nový Bor 1899-1905). ${ }^{83}$ In welch enge Beziehung Elze die protestantische Gemeinde in Laibach zu Truber rückte, zeigen seine zahlreichen ausgezeichneten Arbeiten über den slowenischen Reformator.

Eine bedeutende finanzielle Unterstützung wurde den protestantischen Gemeinden auf slowenischem Gebiet vom „Gustav-Adolf-Verein“ gewährt, denn der Protestantismus fühlte sich in erster Linie als Beschützer der Deutschen. So lesen wir in dem Jahresbericht für Pettau/Ptuj über das „leidvolle Ringen reicher, seelenvoller deutscher Kultur mit seelenloser slawischer Barbarei. [...] Was können wir tun auf dem äußersten Vorposten deutscher Kultur [...]. Wächter freien und frommen deutsch-evangelischen Glaubenslebens müssen wir hier sein sowohl gegenüber den bigott katholischen Slowenen und andererseits bei den untersteirischen katholischen Deutschen, die von ihren Priestern in ihrem Leid im Stich gelassen werden, und die, da ihnen die volksfremde, katholische

80 Laibacher Tagblatt, 248, 29.10.1869.

81 Laibacher Tagblatt 15, 20.1. 1869.

82 Laibacher Tagblatt, 181. 9.8.1869.

83 Breda Dvorak Drašler: Oris nastanka in zgodovine evangeličanske cerkvene občine v Ljubljani. Diplomska naloga. Teološka fakulteta Univerza v Ljubljani 2004. 
Kirche auch innerlich nicht Rechtes mehr zu bieten hat, nur zu leicht aller Religion entfremdet werden." 84

Rudolf Hans Bartsch schildert in seinem Roman „Das deutsche Leid“, der in drei Auflagen erschienen ist, ${ }^{85}$ drastisch die national-konfessionelle Lage in der damaligen Untersteiermark ,Volk [die Slowenen] ist ohne Geschichte, ohne Heldenzeit und Heldenlied, ohne große Beispiele und große Männer, ohne den heißen Drang und Trieb nach Erkenntnis und Forschung. Es fehlt ihm die heilige, lange, läuternde Vorbereitung anderer Kulturvölker, in die sich durch Jahrhunderte das befruchtende Schriftum bis in die Seelen der Weltfernsten, ja der Kinder durchgerungen hat «. ${ }^{86}$ Die Rettung für die Deutschen aus dieser tristen Lage sollte der Protestantismus sein: „Es wird zuviel des Leides und der Feindschaft. Die slawischen Priester fügen uns Weh über Wehe zu [...] wir wollen uns einen Priester aus dem Reiche bestellen. Wir wollen Protestanten werden. ${ }^{67}$ Dann schrieben sie ,ins Reich hinaus um einen deutschen und evangelischen Pfarrer". 88

So ist die slowenische Reformation, wie Primus Truber selbst, in der zweiten Hälfte des 19. Jahrhunderts endgültig zum Opfer der nationalistischen Politik geworden.

\section{Die Wahrnehmung Trubers bei den Slowenen im 19. und 20. Jahrhundert}

Wir erwähnten bereits den Bischof von Lavant, Anton Martin Slomšek, der die Kulturarbeit der slowenischen Protestanten zu würdigen verstand. Mit der Zeit häuften sich die Aufsätze in slowenischer Sprache, zahlreiche Slowenisch Sprechende hatten zuvor nämlich auf Deutsch veröffentlicht.

Die slowenischsprachige Literatur über Truber erlebte am Ende des 19. und zu Anfang des 20. Jahrhunderts einen großen Aufschwung. Eine ernsthafte historische Darstellung der slowenischen Reformation schrieb Josip Gruden in seiner groß angelegten Geschichte des slowenischen Volkes. ${ }^{89}$ Für die slowenische Reformation ist dieses Werk sowie andere Aufsätze in den damaligen wissenschaftlichen Zeitschriften in gewisser Weise immer noch ein geschichtliches Grundwerk.

Truber ist aber auch ein Thema für die Literatur geworden. Der ehemalige Priester und Dichter Anton Aškerc erreichte 1905 mit seiner historischen Heldendich-

84 Jahresbericht der evangelischen Pfarrgemeinde Marburg an der Drau mit Sonderberichten der Vikariate Mahrenberg und Pettau über das Jahr 1911, S. 24.

85 Rudolf Hans Bartsch: Das deutsche Leid. Leipzig 1912, 1917, 1929.

86 Ebd., S. 380.

87 Ebd., S. 324.

88 Ebd., S. 331.

89 Josip Gruden: Zgodovina slovenskega naroda. V Celovcu, Družba sv. Mohorja 1910-1916. 
tung „Primož Trubar“, ${ }^{90}$ dass die Wogen hochgingen. Die Frage „Ist Primus Truber ein Held, der einer Heldendichtung wert ist, oder nicht?" rief eine Polemik hervor. Auf die Kritik reagierte Aškerc betroffen, vor allem traf es ihn, dass sie in „seiner“ Zeitschrift, dem liberalen „Ljubljanski zvon“ erschienen ist. Aškerc benützte die historische Person Primus Truber unter deutschliberalem Einfluss zur Illustration der kulturkämpferischen, kirchenfeindlichen Haltung der liberalen Slowenen. Er heroisierte Truber und seinen Kritikern warf er vor: „Der Herr Doktor ist ein Wissenschaftler“, ${ }^{91}$ aber kein Ästhet. Die These von Aškerc, „Ästhetik und Dichtung" seien wichtiger als Faktentreue, fiel bei den Slowenen auf ziemlich fruchtbaren Boden. Für philologische Untersuchungen gilt dies nicht, aber auch dort werden historische Verhältnisse oft in Aškerc' Sinne dargestellt. In Aškercs Epos rufen slowenische Menschenmengen Truber zu:

„Hej, Trubar! Hoch sollst du leben! Ruhm über dich!

Zur Freiheit soll dein Recht uns führen.

Du bist unser Erwecker und unser Lehrer, slowenischer Prophet und unser Führer"“. 92

Natürlich geht es um die Beziehung zwischen der dichterischen Freiheit und den bekannten historischen Tatsachen. Schon die zeitgenössischen Kritiker weisen darauf hin, dass die historischen Fakten in Aškercs Epos der literarischen Freiheit untergeordnet seien.

Zweifelsohne erregte Aškerc die kulturkämpferischen Gemüter auch in seiner „Hymne der slowenischen Häretiker“, 93 also der slowenischen Protestanten:

„Wir erwählten einen neuen Glauben.

Und nun beten wir zu unserem eigenen Gott; zum Gott der Freiheit, des Lichts und der Wahrheit, und tragen ihn tief in unserem Herzen."

Das Jubiläum des 400. Geburtstags von Primus Truber im Jahr 1908 brachte die bis dahin umfangreichste Gedenkfeier für den slowenischen Reformator. Das Interesse lief in zwei Richtungen: Einerseits ging es um die Suche nach der Verbindung der Reformation mit den sozialen Kämpfen der slowenischen Bauern, den Bauernaufständen, ${ }^{94}$ und andererseits um die Suche nach der kulturellen Be-

90 Anton Aškerc: Primož Trubar. Zgodovinska epska pesnitev. Ljubljana 1905.

91 Anton Aškerc: Ali je Primož Trubar upesnitve vreden junak ali ne? Gospodu profesorju drju. Tominšeku odgovarja A. Aškerc. Ljubljana 1905, S. 4.

92 Ebd., S. 116.

93 Anton Aškerc: Mučeniki. Ljubljana 1906, S. 4.

94 Abditus (Albin Prepeluh): Reformacija in socialni boji slovenskih kmetov. Ljubljana 1908. 
deutung der slowenischen Reformation. ${ }^{95}$ Es erschien die erste Truber und der slowenischen Reformation gewidmete Festschrift. ${ }^{96}$ In diesem Jahr wurde in Ljubljana auch ein Denkmal für Truber aufgestellt. Man kann sagen, dass eine neue, eine slowenische Ära der Wahrnehmung Trubers begann, damit aber auch eine Zeit unterschiedlicher Betrachtungsweisen. Dabei geht es nicht nur um die liberal-klerikale Weltanschauungsfrage, sondern um die Frage eines wissenschaftlichen Ansatzes.

Nach dem ersten Weltkrieg widmete sich Trubers Werken der junge Laibacher Slawist Mirko Rupel. Er gab im Jahr 1934 das Buch „Slowenische protestantische Autoren“ heraus, ${ }^{97}$ mit einer umfangreichen Einleitung zur slowenischen Reformation und mit Abschnitten der Werke von Truber, Sebastijan Krelj, Georg Dalmatin, Adam Bohorič und anderer. Im Jahr 1960 veröffentlichte Rupel die erste umfangreiche Monografie über Truber, ${ }^{98}$ die in deutscher Übersetzung im Jahr 1962 erschien. ${ }^{99}$ Rupel widmete sich außerdem der Suche nach geschichtlichen Quellen, dabei fand er in deutschen Archiven zahlreiche unbekannte Truber-Briefe.

\section{Trubers Wahrnehmung nach dem zweiten Weltkrieg}

Die Wahrnehmung Primus Trubers änderte sich grundlegend nach dem Zweiten Weltkrieg. Hinsichtlich der slowenischen Akzeptanz von Truber und der Reformation waren zwei Elemente ausschlaggebend, und zwar das soziale und das nationale, während das Glaubenselement eine untergeordnete oder keine Rolle spielte, sofern es nicht dem Kampf gegen die katholische Kirche diente. Gemeinsam waren diese herausragenden Elemente sowohl dem katholischen wie dem liberalen und in der Folge auch dem marxistischen Lager, dessen unantastbarer Ideologe in der Nachkriegszeit der hochrangige Politiker Edvard Kardelj war. Die letzte negative Beurteilung des slowenischen Protestantismus aus katholischer Seite schrieb der Geschichtsprofessor an der Laibacher Theologischen Fakultät, Josip Turk im Jahr 1942, wobei sicher auch die deutsche Okkupation eine Rolle spielte: „Die protestantische slowenische Literatur als solche war dem slowenischen Volk in Wahrheit fremd. Bei ihrer Entstehung spielten der deutsche Adel und das Bürgertum eine so große Rolle, dass sie ohne deren Unterstützung damals überhaupt nicht entstehen hätte können. Auch der deutsche Adel und das Bürgertum waren dem slowenischen Volk fremd und bemühten sich nicht um die slowenische protestantische Literatur aus Liebe zum slowenischen Volk als solches. Die Absicht dieser Literatur war vielmehr, unter den Slowenen den deutschen Protestantismus zu verbreiten und zu erhalten, also eine Absicht, die dem

95 Ivan Prijatelj: O kulturnem pomenu slovenske reformacije. Ljubljana 1908.

96 Fran Ilešič (Hg.): Trubarjev zbornik. Ljubljana 1908.

97 Mirko Rupel: Slovenski protestantski pisci. Ljubljana 1934.

98 Mirko Rupel: Primož Trubar, življenje in delo. Ljubljana 1962.

99 Rupel/Saria (wie Anm. 5). 
katholischen slowenischen Volk sicher fremd war. Solch eine Verwendung der slowenischen Sprache war nämlich ein Missbrauch". ${ }^{100}$

Edvard Kardelj brachte eine neue, marxistische Deutung der slowenischen Reformation und des slowenischen Protestantismus. In seinen Ansichten über die Reformation berief er sich natürlich auf Engels: Demnach soll sich auch auf slowenischem Gebiet das feudal-reaktionäre Lager teilweise an den Luther'schen Protestantismus angepasst und dieser den eigenen Interessen dienstbar gemacht haben. Kardelj war das bürgerlich-reformistische Lager sympathischer, nämlich die Schweizer Reformation, da sie dem Kapitalismus und der Herrschaft der Bourgeoisie den Weg bahnte. Am positivsten äußerte er sich über das „bäuerlich-plebejische revolutionäre Lager", das er als Träger demokratischer Tendenzen vorstellte. Kardelj lehrte ,wer sich gegen den Feudalismus erhoben hat, stieß vor allem an dessen ideologische Manifestation, den Katholizismus". ${ }^{101}$ Es waren wieder „Die unentwickelten häretischen Sekten, die sich mit dem allgemeinen revolutionären Brodeln des unterdrückten Volkes verbanden - was unter anderem auch in den Forderungen nach der Demokratisierung der Kirche und dem Recht des Volkes, selbst die eigenen Priester auszuwählen, zum Ausdruck kam - [diese Sekten] erleichterten und bereiteten unmittelbar das Erscheinen einer organisierten protestantischen Bewegung vor, deren Hauptideologe und Organisator auf slowenischem Boden Primož Trubar wurde." 102 Kardelj spricht der slowenischen Reformation eine gewisse Bedeutung für die nationale Affirmation der slowenischen Bevölkerung zu, er meint jedoch, dass Truber wegen seiner Verbindung mit dem Adel die Bauern sehr bald abgestoßen habe.

Nichts Positives fand Kardelj an der Gegenreformation, weil diese, seiner Meinung nach, „Die römisch-katholische Kirche festigte und [sie] gründete in einem entscheidenden geschichtlichen Augenblick des slowenischen Volkes eine fremde Hegemonie auf slowenischem Boden“". ${ }^{103}$

Das nationale Dilemma löste Kardelj auf der Grundlage eines Erlasses des AVNOJ (Antifaschistische Bewegung der Volksbefreiungsarmee Jugoslawiens) vom 21. November 1944, der bestimmte, dass das gesamte Vermögen des Deutschen Reiches und der Personen mit deutscher Volkszugehörigkeit auf jugoslawischem Hoheitsgebiet zu beschlagnahmen sei. Darauf wurde das Vermögen aller protestantischen Gemeinden in Slowenien konfisziert - außer in Prekmurje, das heißt im Gebiet jenseits der Mur -, die Kirchen geräumt und geschlossen. Die revolutionären Errungenschaften wurden auch mit menschlichen Opfern bezahlt. Josip Benko, Unternehmer und Senioratsinspektor der evangelischen Kirche in Murska Sobota, wurde 1945 zum Tode verurteilt und exekutiert. Im Jahr 1993 wurde der Prozess neu aufgerollt und Benko gerichtlich freigesprochen.

100 Josip Turk: Vpliv protestantizma na slovenski narod. In: Revija katoliške akcije. Ljubljana 1942, S. 127.

101 Edvard Kardelj (Sperans): Razvoj slovenskega narodnega vprašanja. ${ }^{3} 1977$, S. $169 \mathrm{ff}$.

102 Ebd., S. 171.

103 Ebd., S. 185. 
Die Kirchengemeinde in Laibach wurde im Jahr 1976 erneuert und erhielt 1992 ihr Vermögen rückerstattet. Heute trägt die protestantische Kirche in Ljubljana den Namen Primož Trubars.

Wie wird Truber heute wahrgenommen? Sein Werk und das Werk anderer slawischer Protestanten wird an zahlreichen Instituten studiert. Die ersten großen Feiern für Truber fanden im Jahr 1950 statt, anlässlich des 400. Jahrestages des Erscheinens des ersten slowenischen Buches. Im Jahr 1952 erschien der zweite Truber-Sammelband „Drugi Trubarjev zbornik“ . ${ }^{104}$ Redakteur dieses Buches war der oben genannte Mirko Rupel. Im einführenden Beitrag „Die sozialpolitische Basis der Reformbewegung auf slowenischem Gebiet" stellt Boris Ziherl die Reformationszeit des 16. und Anfang des 17. Jahrhunderts aus marxistischer Sicht dar, als „Höhepunkt der ersten Epoche der revolutionären Bewegung gegen den Feudalismus, eine Zeit, in der die Bewegung überwiegend in religiösen Kämpfen ihren Ausdruck fand“. Für die slowenischen protestantischen Autoren, und hier vor allem für Truber, stellt er fest, dass sie „gegenüber den Befreiungsbemühungen der plebejisch-bäuerlichen Massen und ihren ideologischen Ausdrucksformen eine ablehnende Haltung vertraten“. Indem er die Haltungen von Luther und Truber zu den Bauernaufständen vergleicht, kommt Ziherl zur Auffassung, dass ,während Luther zur Zeit der deutschen Bauernaufstände den Adel dazu anstiftete mit den Rebellen blutig abzurechnen, gestattete es Truber seine Verbundenheit mit dem heimatlichen Boden und seinen Menschen nicht, sich einseitig auf die Seite der adeligen Unterdrücker zu stellen." ${ }^{105}$ Seine Haltung gegenüber den Akteuren im großen slowenisch-kroatischen Bauernaufstand von 1573 deutet Ziherl als Haltung eines politischen Opportunisten, der einerseits die Bauern beschwichtigt und sie vor unüberlegter und aussichtsloser Rebellion warnt und andererseits die Schlossherren, den Adel, von einer unmenschlichen Behandlung der Leibeigenen abhalten will, könnten sie doch damit der Strafe Gottes in dieser oder der jenseitigen Welt teilhaftig werden. An dieser Stelle beruft Ziherl sich auf Edvard Kardelj, der schreibt, dass „die protestantischen Bücher die Rolle des ideologischen Organisators der slowenischen Nation gespielt haben. In diesem Sinne können wir also ohne Übertreibung sagen, dass die Reformation und die Bauernaufstände den Grundstein der slowenischen Nation gelegt haben." ${ }^{106}$

Trotz dieser ideologisch-politischen Richtlinie beinhaltet der Tagungsband aus dem Jahre 1952 doch auch sehr wesentliche wissenschaftliche Beiträge. Dazu zählt sicherlich der Beitrag von Mirko Rupel „Truber und die Formula concordiae". Rupel weist auf die zentrale Rolle Trubers hin, der die Landstände von Krain, der Steiermark und Kärntens bewog, die Formula concordiae zu unterzeichnen.

104 Rupel (uredil) (wie Anm. 20).

105 Boris Ziherl: Družbenopolitični temelji reformacijskega gibanja na slovenskem. In: Rupel (uredil) (wie Anm. 20), S. 7-14, hier S. 9.

106 Ebd., S. 14. 
Rupel erwähnt in seinem Beitrag die Namen aller Unterzeichner aus Krain und veröffentlicht 25 Briefe, die im Zusammenhang mit der Unterzeichnung der Formula concordiae entstanden sind. Das dies keine leichte Aufgabe für Truber war, obwohl er auf die Unterstützung der württembergischen Theologen und des Herzogs von Württemberg zählen konnte, zeigt die erwähnte Korrespondenz und die bis zur Unterzeichnung von 1579 bis 1582 sich hinziehende Dauer der Aktion, bis die Landstände aller drei Länder ihre Unterschrift leisteten.

Nach Auffassung seines Biographen Mirko Rupel soll Truber für diesen Erfolg seine von der deutschen reformatorischen Ausrichtung abweichende Linie geopfert haben „Die Konkordienformel war im Grunde genommen ein Abweichen von den ursprünglichen reformatorischen Grundsätzen, ein stures und strenges Gesetzbuch, gedacht als gewaltsames Mittel gegen jegliche freiere Glaubensüberzeugung. In jungen Jahren hätte sich Truber wohl auch widersetzt, wie sich ihr auch jetzt einige Lutheraner widersetzten. Dem 72-Jährigen, der schon lange in der offiziellen lutherischen Kirche lebte, war die Formel jedoch ein Mittel, durch das in seiner Heimat eine eventuelle häretische Richtung verhindert werden konnte. In der Unterzeichnung derselben sah er jedoch vor allem eine Kundgebung seiner Landsleute für ihren Glauben, zugleich auch einen Schachzug gegen die fortschreitende Gegenreformation, die sein Lebenswerk zu vernichten drohte". ${ }^{107}$

Als neuer Meilenstein für die Wahrnehmung Primus Trubers könnte der 400 . Todestag Trubers im Jahr 1986 bezeichnet werden. Diesen Jahrestag markierten zahlreiche Symposien und Publikationen. Als bahnbrechend könnte dabei das Symposium „Ein Leben zwischen Laibach und Tübingen - Primus Truber und seine Zeit. Intentionen, Verlauf und Folgen der Reformation in Württemberg und Innerösterreich“ das vom 3. bis 8. November 1986 in Tübingen stattfand, bezeichnet werden, der Tagungsband hierzu erschien 1995. ${ }^{108}$ Bei diesem Symposium versammelten sich erstmals Historiker, Theologen, Soziologen und Literaturwissenschaftler aus Deutschland, Slowenien, Österreich, Kroatien, Serbien, Bulgarien und Moldavien. Es markiert den Beginn einer Periode, in der Truber, als verbindendes Element gesehen wird, und nicht mehr Gegenstand einer Vereinnahmung durch nationale, ideologische und konfessionelle Interessen ist. In Ljubljana fand das Symposium „Reformacija na Slovenskem. Ob štitistoletnici smrti Primoža Trubarja“ vom 9. bis 13. November 1987 statt. Der Sammelband erschien als „III. Trubarjev zbornik“ im Jahr 1996. ${ }^{109}$

107 Mirko Rupel: Primož Trubar in Formula Concordiae. In: Rupel (uredil) (wie Anm. 20), S. 65112, hier S. 65; Rupel/Saria (wie Anm. 5), S. 259.

108 Rolf-Dieter Kluge (Hg.): Ein Leben zwischen Laibach und Tübingen - Primus Truber und seine Zeit. Intentionen, Verlauf und Folgen der Reformation in Württemberg und Innerösterreich. München 1995.

109 Franc Jakopin / Marko Kerševan / Jože Pogačnik (uredili): III. Trubarjev zbornik. Prispevki z mednarodnega znanstvenega simpozija „Reformacija na Slovenskem. Ob štiristoletnici smrti Primoža Trubarja“. Ljubljana, 9.-13. November 1987. Ljubljana 1996. 
Ohne Bezug auf einen Jahrestag und ohne Anregung durch eine Tagung publizierte der Kärntner evangelische Bischof Oskar Sakrausky im Jahr 1989 seine langjährigen Studien unter dem Titel „Primus Truber. Deutsche Vorreden zum slowenischen und kroatischen Reformationswerk". ${ }^{110}$ Diese umfangreiche Arbeit bezeugt ein großes Engagement für eine national- und ideologiefreie Darstellung und Akzeptanz Trubers. Die in einem Band zusammengefasst publizierten deutschsprachigen Vorworte Trubers, ausgestattet mit umfangreichen theologischen und historischen Kommentaren, erleichtern wesentlich die Forschungsarbeit.

Die internationale Zusammenarbeit wurde fortgesetzt und erreichte 2008 anlässlich Trubers 500. Geburtstag einen neuen Höhepunkt. Mit zahlreichen Symposien und anderen Veranstaltungen in Slowenien und im Ausland, unter den zahlreichen Symposiumsteilnehmern sei insbesondere die ausgezeichnete Zusammenarbeit zwischen den deutschen, österreichischen und slowenischen Wissenschaftlern zu erwähnen, spiegelt sich doch in der gemeinsamen Erforschung und Bewertung der Reformation der einheitliche staatliche Raum der Entwicklungen im 16. Jahrhundert wider. Die Zusammenarbeit blieb jedoch nicht auf die genannten Länder beschränkt, sondern es wurden auch Experten aus dem breiteren mitteleuropäischen Raum hinzugezogen. Da es unmöglich ist, eine umfassende Bibliographie zu präsentieren, werde ich nur auf einige der wichtigsten Werke hinweisen.

In Ljubljana erschien im Jahre 2009 der Sammelband „Glaube und Willen“ des Symposiums „Novi pogledi na Primoža Trubarja in njegov čas (Neue Blicke auf Primus Truber und seine Zeit), 9.-10. Oktober 2008“.111

Im Jahr 2011 erschienen zwei wichtige Publikationen, die Truber in einem größeren europäischen Kontext vorstellen. Die erste mit dem Titel „Primus Truber. Der slowenische Reformer und Württemberg"112 ist wiederum eng mit Tübingen verbunden und wird von ihren Verlegern im Vorwort mit folgenden Worten vorgestellt: „Seit dem Truber-Gedenken von 1986 sind jedoch nicht nur die politischen Rahmenbedingungen in Trubers Heimat völlig andere geworden, sondern auch die vergleichende Forschung zur Reformationsgeschichte ist vorangekommen“. Eine Persönlichkeit wie Primus Truber kann angemessen nur in einer interdisziplinären Sicht gewürdigt werden. Historiker, Theologen, Sprach- und Literaturwissenschaftler, Buchwissenschaftler und Kunsthistoriker haben zu diesem Sammelband beigesteuert“. Als nächste ist die Publikation der Tagung in Wien „Die Reformation in Mitteleuropa“"113 zu erwähnen, die Truber in einen Kontext auch außerhalb der Grenzen des Heiligen Römischen Reiches stellt.

110 Sakrausky (wie Anm. 16).

111 Sašo Jerše (uredil): Vera in hotenja. Študije o Primožu Trubarju in njegovem času. Ljubljana 2009.

112 Lorenz/Schindling/Setzler (wie Anm. 3).

113 Rajšp/Schwarz/Dybaś/Gastgeber (wie Anm. 32). 
Die Erinnerung an Truber wird auch durch eine Reihe von Gedenktafeln in Orten, in denen Truber in Slowenien, Italien (in Sovodnje/Savogna) und Süddeutschland gewirkt hat, bewahrt. ${ }^{114}$ Die jüngste Tafel wurde am 17. März 2017 in Schwäbisch Hall in Erinnerung an den Druck der ersten beiden slowenischen Bücher, deren Autor Trubar war, enthüllt..15

$\mathrm{Zu}$ erwähnen ist noch die neue slowenische Zeitschrift „Stati inu obstati“ (Stehen und bestehen) ab dem Jahr 2005, die der slowenischen Reformation gewidmet ist, die international orientiert ist und viele Aufsätze über Primus Truber bringt. So können wir hier auf die ausgezeichnete Zusammenarbeit deutscher, österreichischer, kroatischer, ungarischer, italienischer, polnischer und anderer mitteleuropäischer Wissenschaftler hinweisen.

Wir wissen viel, aber wissen wir auch, was Truber wirklich sagte und was er uns heute zu sagen hätte? Die Frage ist aktuell und aus slowenischer Sicht in dem Aufsatz von Sašo Jerše »Die slowenische Reformation zwischen dem Amboss Christi und dem Hammer der Romantik - Zur Hagiographie der Moderne und deren vormodernen Grenzen « treffend dargestellt. ${ }^{116}$

Ich denke, dass uns Truber vor allem als Vorbild bei der Suche nach der Wahrheit dessen sein kann, was das Wesen seiner Predigten ist. Truber verkündete in erster Linie den Glauben an Gott, an Jesus Christus, der ständig von der negativen Kraft, dem Teufel, begleitet werde. Über dieses zentrale Anliegen Trubers war allerdings in der ersten Hälfte des 20. Jahrhunderts wenig zu hören. Vielmehr wurde Trubers religiöse Botschaft von den ideologischen Lagern des Nationalsozialismus mit der Vertreibung der slowenischen katholischen Geistlichen und des Kommunismus (Tito, Kardelj) mit der Vernichtung des „,deutschen“ Protestantismus, für die jeweils eigenen Zwecke benützt.

Abschließend kann festgestellt werden, dass die Auslegung Trubers in Bezug auf Ideologie, Nationalismus und sogar Konfessionalismus in der Vergangenheit keine zufriedenstellenden Antworten gegeben hat. Seit den 80er Jahren des 20. Jahrhunderts bieten aber die weitgehend ideologiefreie Wahrnehmung Trubers und die neue ökumenische Ausrichtung eine zukunftsweisende Perspektive im europäischen Kontext.

114 Anton Schindling: Primus-Truber-Gedenkorte in Süddeutschland. In: Carinthia I 203 (2013), S. 167-183.

115 Helmut Claus: „Gedruckt in Siebenbürgen ...“ im vorliegenden Band, S. 45-58.

116 Sašo Jeř̌se: Die slowenische Reformation zwischen dem Amboss Christi und dem Hammer der Romantik - Zur Hagiographie der Moderne und deren vormodernen Grenzen. In: Jahrbuch für die Geschichte des Protestantismus in Österreich 129 (2013), S. 128-150. 